\title{
EL PALEOLÍTICO ANTIGUO EN ASTURIAS
}

\section{THE LOWER PALAEOLITHIC IN ASTURIAS}

\author{
por \\ JOSÉ ADOLFO RODRÍGUEZ ASENSIO ${ }^{1}$
}

\begin{abstract}
"Las industrias líticas del paleolítico Medio en formaciones fluviales de la península Ibérica resultan netamente diferenciadas de los complejos musterienses, que podemos llamar clásicos, de cuevas y covachos (....) Esta diferenciación radica en el aspecto postachelense de las industrias desarrolladas en los medios fluviales y, a mi modo de ver, debe entenderse como el resultado de una tradición de las industrias de graveras en todo el gran área inferopaleolítica peninsular, en un fenómeno de perduración de sus viejos sustratos tecnotipológicos en el paleolítico Medio."
\end{abstract}

Enrique Vallespí Pérez (1989: 7) "Paleolítico medio indeterminado, de aspecto postachelense, en ámbitos fluviales del sur y centro de la península Ibérica".

RESUMEN En Asturias el paleolítico Antiguo en el que se incluyen las culturas achelense y musteriense se encuentra representado en varios conjuntos repartidos por toda la geografía regional y de manera fundamental en la Rasa litoral y en las terrazas fluviales del interior. Yacimientos en la desembocadura de río o en Ensenada, en terraza fluvial o en valle interior son tipos que han sido identificados en esta zona. Se propone una secuencia cultural y cronológica continua desde el pleistoceno Medio hasta el würm antiguo muy relacionada entre sí, en la cual se ordenan momentos culturales del Achelense en general, del Achelense superior, del Musteriense de tradición achelense al aire libre y del Musteriense de tradición achelense en cueva

ABSTRACT In Asturias country Old Palaeolothique in which the the Acheulean and Mousterian cultures are included in present at many lithics groups distributed over all regional geography and specially in littoral Rasa and inland fluvial terraces.. Sites in the mouth of the river or in inlet, in fluvial terrace or inland valley are kinds of sites that have been identified in this zone. We propose a continuous cultural and chronological sequence very related each other from the middle Pleistocene period to old Wüm in which cultural moments of the Acheulean in general ordered, of the upper Acheulean, of the Mousterian of acheulean tradition in the open air and the Mousterian of acheulean tradition in cave.

1. Área de Prehistoria. Universidad de Oviedo. Campus El Milán. C/ Tnte. Alfonso Martínez s/n. 33011. Oviedo. E. Mail: adolfo@correo.uniovi.es.

ISSN: 1133-4525 ISSN-e: 2255-3924

SPAL 9 (2000): 109-123

http://dx.doi.org/10.12795/spal.2000.i9.05 
Palabras claves Asturias. Norte de la península Ibérica. Paleolítico Antiguo. Paleolítico Inferior. Paleolítico Medio. Achelense. Musteriense de tradición achelense

Key words Asturias. North of Iberica peninsula. Old Palaeolithique. Lower Palaeolithique. Middle Palaeolithique. Acheulean. Mousterian of the acheulean tradition.

\section{INTRODUCCIÓN}

Escribir una síntesis sobre el paleolítico Antiguo en Asturias para integrarla con las de las demás zonas peninsulares con la intención de disponer de un panorama de las poblaciones paleolíticas en estas lejanas etapas resulta altamente sugerente. Esta característica, ya de por sí, suficientemente importante para animarnos a realizar esta labor, cobra una dimensión mayor si se le añade la característica de hacerlo en homenaje a uno de los estudiosos de estas épocas más importante, como es el caso del Prof. Dr. Enrique Vallespí Pérez con quien hemos tenido ocasión de compartir muchas experiencias de este estudio, durante su estancia en la universidad ovetense que, aunque breve, fue muy fructífera desde el punto de vista docente. En la parte gráfica de este artículo han colaborado José Barrera Logares, Eugenio Aguilar Huergo y María Noval Fonseca quienes se suman, también, a esta merecida distinción al profesor de la Universidad de Sevilla.

Las investigaciones sobre el más antiguo paleolítico en Asturias se remontan a los primeros años del siglo XX en que se producen algunos hallazgos y que están muy relacionados con los estudios de las cuevas con paleolítico superior y con arte paleolítico que se estaban llevando a cabo en el Cantábrico. La asignación de aquellos materiales se hace en función de las características tipológicas y tecnológicas al uso y también su integración cultural, de manera que se empieza a hablar de yacimientos o sitios o simplemente de materiales líticos del Achelense o del Musteriense como los dos momentos anteriores a los niveles del paleolítico superior que tan abundantemente se estaban señalando en esta zona y que, poco a poco, iban perfilando la secuencia cultural y cronológica que ha llegado hasta nosotros y hoy se sigue manteniendo con algunas variante y detalles muy concretos. Los cercanos yacimientos con completas estratigrafías, como es el caso de la vecina cueva cántabra de El Castillo, sirvieron de referencia para establecer un esquema que se adentraba en los lejanos momentos más allá de la última glaciación (Würm) y de la anterior etapa interglaciar (RissWürm). Hallazgos en superficie y en cueva pero sin contexto estratigráfico permitieron hablar del paleolítico inferior y del paleolítico medio intentando su reconstrucción con muy escasos materiales, algunas veces de dudosa procedencia y otras de no menos dudosa asignación cultural.

Estos dos tipos de sitios, los encontrados al aire libre y los situados en cueva, se separaron definitivamente yendo por caminos de investigación diferentes y, así, los primeros fueron objeto de una intensa prospección, búsqueda y primeras valoraciones, mientras que los segundos se detendrían en los datos antiguos aportados por las cuevas de Arnero (Obermaier 1916), Samoreli (Cabré 1915), La Cuevona (Jordá 1955) y El Conde (Freeman 1977; Márquez Uría 1977), hasta el momento presente en que se ha llegado en excavaciones a niveles antiguos en diferentes cuevas como La Viña (Fortea 1998) y Llonín (Fortea et al. 1998) que han aportado los primeros datos musterienses estratigráficamente contrastados.

En la década de los ochenta plateamos (Rodríguez Asensio 1983) la primera síntesis de las etapas más antiguas de la presencia humana en Asturias, es decir, el paleolítico inferior y medio, estableciéndose una distribución regional y unas características tecnológicas y tipológicas de los abundantes materiales rescatados, sobre todo, al aire libre. Las primeras excavaciones y sondeos en diferentes sitios con características distintas nos permitieron definir los distintos tipos de yacimientos existentes en esta región. Remitimos para el detalle y para el análisis de las diferentes etapas transcurridas en este casi siglo de investigaciones inferopaleolíticas 
al completo trabajo historiográfico (Barrera 1998) en que se analizan todas las obras, autores y planteamientos metodológicos del estudio del paleolítico antiguo en Asturias.

En estos últimos años se han llevado a cabo estudios de campo y de laboratorio que han confirmado y fortalecido las hipótesis planteadas casi veinte años atrás, de manera que proponemos elevarlas a la categoría de conclusiones; al menos las que a continuación establecemos y que nos permiten abordar una síntesis del poblamiento antiguo y sus características desde el inicio hasta el gran cambio que se produce al comienzo del paleolítico superior cuando se dan las auténticas y verdaderas variaciones, como son las que se refieren al tipo humano; a la tecnología y tipología lítica y ósea; a la especialización en las actividades de caza y aprovechamiento de los recursos naturales; a la organización de los yacimientos y a la aparición y desarrollo de determinadas prácticas relativas al mundo anímico, como es el caso del arte paleolítico. Todo ello hace que marquemos estos momentos, amplios por otra parte, además, como el final de todo un proceso anterior y que nosotros hemos preferido denominarlo paleolítico antiguo cuyas diferencias interiores se muestran, las más de las veces, débiles y endebles y solamente basadas en meras características tipológicas muy difíciles de individualizar. Idea esta apuntada por nosotros (Rodríguez Asensio 1983) y por otros autores (Vallespí 1989) y que en la actualidad se puede rastrear en el pensamiento prehistórico moderno (Gamble 1990; Mithen 1998).

Nuestra concesión, por otra parte tradicional, al culturalismo, del cual se nos hace muy difícil prescindir, la hemos reducido al máximo y de ella hemos desechado subdivisiones excesivas, al menos así lo creemos y hemos escapado de denominaciones tales como "premusteriense" por resultarnos de imposible definición y que inducen más a la confusión que a aclarar la larga y compleja etapa que nos ocupa. Por tanto, sólo hablamos de culturas achelense y musteriense. Es cierto que en ambas se pueden rastrear diferencias importantes en los materiales y que han sido vistas como definitorias de distintos momentos cronológicos y así, en las primeras se introducen subdivisiones de medio y superior; mientras que en las segundas se ha intentado y se sigue haciendo un denodado esfuerzo por encajarlas en las, ya de por sí difíciles, "facies musterienses" del tradicional paradigma del famoso profesor de Burdeos (Bordes 1950; 1961; Bordes \& Bourgon 1951). Nuestro escepticismo a aplicar esos esquemas nos ha llevado, asimismo, a un planteamiento similar de las etapas anteriores, de manera que nuestros análisis de los materiales y nuestros estudios de campo nos permiten poner el acento de una manera más fuerte en circunstancias menos antrópicas y más naturales como son las características de la materia prima que es absolutamente tiránica y que va a marcar de forma rígida las formas y los tipos instrumentales o las referidas al medio ambiente, las cuales han permitido y, seguramente potenciado, las diferencias que, a veces, se nos antojan muy grandes y que pueden no serlo tanto. Es cierto, y más adelante nos detendremos en ello, que en Asturias hemos encontrado evidencias líticas más antiguas que las, hasta ahora definidas en el Cantábrico, que hemos situado en el pleistoceno Medio (Rodríguez Asensio $1995 ; 1996 ; 1998 ; 1999)$ y que no hemos definido culturalmente pues, además de ser muy escasas todavía, su inclusión en el esquema cultural tradicional no aportaría nada nuevo y es posible que sí indujera a error $\mathrm{o}$, al menos, a una comprensión sesgada. Aunque en ocasiones las hemos denominado como preachelenses o paleoindustrias, ambos términos deben ser entendidos dentro del contexto cantábrico y nunca de manera general.

\section{CARACTERÍSTICAS}

Asturias forma parte de la denominada cornisa cantábrica que muestra una unidad medioambiental y unas características similares que, salvo detalles, que, por otra parte, son muy importantes, nos permiten extrapolar las conclusiones logradas en determinados yacimientos y hacerlas extensivas a todo el norte peninsular. No obstante, las diferencias, a veces muy marcadas, en la investigación y en la metodología aplicada han llevado a una visión excesivamente parcelada y a considerar erróneamente demasiadas diferencias 
en esta zona, al menos en lo que se refiere al poblamiento antiguo. Así el paleolítico Antiguo en Asturias debe ponerse en relación con el paleolítico Antiguo en Cantabria y en Euskadi, cuyas síntesis más importantes han sido planteadas, respectivamente por Montes Barquín (1993; 1998) y Baldeón (1987; 1990). Es cierto y, aunque no podemos detenernos en detalle en este breve resumen, no podemos olvidarlo, en las diferentes zonas se ha hecho más o menos hincapié en determinadas características que confirmasen los esquemas culturales preestablecidos y permitiesen verlos como válidos en un paradigma ya anteriormente aceptado. Así, mientras en Asturias la ausencia, hasta ahora, de yacimientos en cueva con niveles musterienses bien definidos permitió que la inflexión se pusiese más en los yacimientos al aire libre; en Cantabria la estratigrafía de la cueva del Castillo en la que niveles achelenses y musterienses han sido definidos desde antiguo (Cabrera 1984) y las cuevas de Morín (González Echegaray et al. 1971; 1973) y El Pendo (Freeman 1980) estudiadas con posterioridad hicieron que achelenses y musterienses fuesen analizados por separado y apareciese en escena la definición del Musteriense cantábrico (Freeman 1969-70; Cabrera 19983) a partir de la facies vasconiense de F. Bordes (1953). Por último, las investigaciones en Euskadi acentuaron más la denominada cultura musteriense y sus subdivisiones internas, basándose en yacimientos clásicos con niveles en los que se ha definido esta cultura como Lezetxiki (Baldeón 1993) o Axlor (Baldeón 1999). Además, en el caso vasco, las fechas aportadas para la primera de estas cuevas en los niveles más bajos, con resultados numéricos cercanos al 300.000 permitía hablar de musterienses muy antiguos que fueron definidos como premusterienses (Baldeón 1993) y establecer una secuencia poblacional y cultural desde muy antiguo sin necesidad de acudir a culturas del paleolítico Inferior, es decir, achelenses. Este planteamiento puede deberse a una aceptación demasiado rígida de los caracteres tecnológicos y tipológicos definitorios del achelense y del musteriense que, además, han sido vistos, en no pocas ocasiones, como excluyentes entre sí, lo cual, a nuestro modo de ver, no resulta adecuado. Estas fechas, por otra parte, ya desde su publicación han sido puestas en cuarentena por el método utilizado que, como bien es sabido, está basado en los análisis de U/Th y ESR y tal como ya advierte Altuna (1992) “...es sabido que las dataciones mediante la serie del Uranio a partir de los huesos no ofrecen, ni mucho menos, la garantía que ofrecen a partir de otros materiales, tales como estalagmitas compactas", por lo que, aunque no deban ser desechadas sí, al menos, deben mantenerse sobre ellas unas ciertas reservas.

Por ello, no resulta nada sencillo hablar de un Achelense o de un Musteriense en el Cantábrico, a no ser que se haga yacimiento por yacimiento o zona por zona y ello no nos permite abordar una síntesis general. No es nuestra intención hacer aquí una crítica ni de yacimientos ni de zonas pero quizás ésta deba emprenderse ahora que ya se dispone de suficientes datos modernos de prospecciones y de excavaciones, etc., y hacerlo con una misma metodología. Si no es así seguiremos estancados en la duda siempre que hablemos de achelense o musteriense siendo necesario e imprescindible explicar a qué nos estamos refiriendo cuando empleamos estos términos.

En Asturias que es nuestro objetivo aquí y ahora, proponemos un esquema que desarrollamos a continuación y, aunque alguno de sus extremos deba ser visto todavía como hipótesis, otros, no obstante, pueden ser aceptados ya con una cierta seguridad con las lógicas reservas que toda investigación de estas características precisa.

\section{DISTRIBUCIÓN GEOGRÁFICA Y TIPOS DE YACIMIENTOS}

Ya desde hace años (Rodríguez Asensio 1983) hemos definido un mapa de distribución del poblamiento antiguo del paleolítico en Asturias y, así, se han individualizado dos grandes zonas generales que desde ese momento han ido cobrando una mayor personalidad gracias a las investigaciones en ellas llevadas a cabo y hoy día han sido asumidas de una manera más o menos general. Si observamos el mapa de la distribución de los yacimientos en Asturias detenidamente, nos damos cuenta que dejando de lado las cadenas montañosas 
y las alturas superiores a la cota de 800 metros que hemos situado como límite más allá del cual no hay posibilidad de encontrar restos de estas épocas, vemos un cierto poblamiento que más o menos ocupa, de una manera general, todas las demás tierras astures. Como es lógico, para la total comprensión de este mapa debe tenerse en cuenta, además, que las investigaciones prehistóricas, prospecciones y excavaciones no han tenido la misma intensidad en todos los sitios por diferentes circunstancias de muy diversa índole. Así, algunos de los vacíos que aparecen en este mapa y que pueden resultar un tanto chocantes son debidos a una simple falta de prospecciones y no han de ser achacados a otras causas más complejas y relacionadas con el poblamiento antiguo. Simplemente es que en algunos sitios no se han buscado restos de estas épocas y, como es lógico, si no se buscan no se encuentran.

Dentro de esta distribución general se puede llegar a una cierta división en dos grandes zonas, tal como en su día proponíamos, es decir, una gran área de asentamiento humano en la costa cantábrica en la que se encuentra una plataforma lisa y ancha, como es la rasa litoral, que permitiría la movilidad de estos grupos de una manera relativamente cómoda. En esta rasa litoral y en las tierras aledañas hemos encontrado restos de diferentes yacimientos, desde la vecina costa de Lugo hasta la opuesta vecina de Cantabria. Como es sabido, no toda la costa presenta las mismas características geomorfológicas y donde mejor se ha podido identificar esta área de poblamiento y en la que se han rescatado más cantidad de restos arqueológicos es en la parte occidental donde, además, se ha definido más claramente la rasa litoral cantábrica. En ella hemos distinguido una serie de zonas que llamamos, como hipótesis de trabajo, "territorios de caza" en los cuales hay un yacimiento de importancia grande y en su entorno se han rescatado, además, series más o menos numerosas de materiales líticos y piezas sueltas que demuestran el movimiento en la zona de algún grupo humano. En estos sitios se localiza siempre un río que, en este caso de la plataforma costera, se trata de desembocadura, que marca un cierto eje natural en torno al cual se desarrollarían las actividades del grupo humano. Sin pretender ser exhaustivos en esta distribución y aun manteniendo una cierta prudencia a la hora de extraer conclusiones, llamamos la atención del "territorio" de Cabo Peñas en el cual el yacimiento que lo individualiza es Bañugues. Esta ensenada, en la que desembocan dos importante arroyos ofrece todo lo necesario para un establecimiento más o menos duradero (Rodríguez Asensio 1983; Rodríguez Asensio et al. 1980); el "territorio" de Gijón donde, quizás en la zona de Viesques por la que transcurría un cauce fluvial importante, se encontrase el yacimiento base (Rodríguez Asensio et al. 1998); el "territorio" de Cabo Busto en el que el yacimiento del mismo nombre es el más importante de la zona (Rodríguez Asensio et al. 1999; Rodríguez Asensio 2001). Aquí la desembocadura del río Esva marcaría las características medioambientales de la zona; el "territorio" de San Martín cercano a la desembocadura del río Negro; el "territorio" del Porcía donde el río del mismo nombre desemboca en el Cantábrico; el "territorio" de Louselas relacionado con el río Eo que hace de frontera natural entre Asturias y Galicia (Rodríguez Asensio 1997).

En la rasa litoral hemos reconstruido una estratigrafía gracias a los trabajos arqueológicos llevados a cabo, de manera especial, en los yacimientos de Bañugues y Cabo Busto en los que las excavaciones nos han proporcionado una secuencia geológica y preciados datos cronológicos, extrapolables a otros sitios en los que también hemos podido individualizar los mismos niveles. El yacimiento que más datos nos ha proporcionado es el de Cabo Busto donde hemos determinado varios niveles sedimentológicos y en dos de ellos, el II y el V, hemos recuperado restos de un asentamiento en el primero y evidencias líticas en el segundo.

No hemos de ver esta distribución de una manera rígida en el sentido de ubicar determinados lugares de asentamiento estables y permanentes en cada una de estas zonas sino, más bien, se trata de una manera de distribuir el territorio asturiano en áreas más pequeñas en las que las actividades humanas puedan ser desarrolladas dentro de un sistema de movilidad permanente como sería el que caracterizase a estos grupos humanos. No acudamos a rígidas y forzadas comparaciones etnológicas para dar significado a estos "territorios" pues no haría justicia a la idea que aquí pretendemos exponer y que no va más allá de una distribución espacial que, además, viene marcada por diferentes conjuntos líticos con características distintas en el tipo 
de instrumentos y en el número de los mismos. Quizás sea aun prematuro intentar diferenciaciones entre los yacimientos según el tipo de asentamiento y nosotros aquí no lo intentaremos, aunque es cierto que del estudio detallado y pormenorizado de los materiales líticos se observan diferencias sustanciales que han de ser interpretadas en esta línea y no ya en otras direcciones que hasta ahora han marcado complejas y difíciles subdivisiones culturales, a veces, muy difíciles de ordenar y de situar en un marco general de la Prehistoria. Nos referimos a que más que diferencias culturales, por ejemplo, dentro del achelense superior o final, que ya de por sí presenta enormes dificultades de definición, han de intentar comprenderse las diferencias en las series líticas como fruto de las distintas actividades llevadas a cabo en una zona o en otra. Esto que, por otra parte, es admitido teóricamente, de una manera incontestable, no siempre es aplicable al estudio de los yacimientos del paleolítico Antiguo.

Una segunda zona en Asturias, importante en la localización de materiales prehistóricos de estas épocas se sitúa en la parte central de la región en la que se encuentran los cauces de los más importantes cursos fluviales, entre los que destaca el río Nalón. En las terrazas fluviales de este curso y de sus afluentes, sobre todo en la cuenca media y baja, es donde los numerosos restos líticos encontrados en diferentes sitios nos han permitido establecer una cierta estratigrafía muy relacionada con la secuencia de las terrazas y que, todavía de manera provisional, pero con los suficientes datos arqueológicos para que sea una hipótesis de trabajo a tener en cuenta, exponemos como tal. La sucesión de terrazas fluviales que mejor se pueden seguir en los concejos de Siero, Oviedo, Las Regueras, Candamo y Pravia nos muestra una secuencia de varios aterrazamientos que según Hernández Pacheco et al. (1957) y Hoyos (1981) se sitúan en número de 6, desde la actual de inundación hasta la que se encuentra a los 90 metros. Nuestras pesquisas y prospecciones y las búsquedas anteriores (González 1968) han permitido rescatar conjuntos industriales en algunas de estas terrazas y así, desde la más baja, en la que hemos encontrado restos de conjuntos cuya tipología nos ha permitido situarlos en un Musteriense de tradición achelense, hasta la más alta que conecta, además, en la desembocadura del Nalón, con la rasa litoral en niveles que estarían relacionados con el V de Cabo Busto, en la que los materiales recuperados se han clasificado dentro del Achelense, en momentos más antiguos. Recuérdese que Busto V, debido a sus escasas evidencias líticas, lo mantenemos aun con términos de "paleoindustrias" y sin incluir en ninguna subdivisión antigua del Achelense. Sea como fuere, y no creemos que ahora sea lo más importante asignar una clasificación a estos restos más antiguos, lo cierto es que en la terraza más alta se encuentran los materiales más antiguos tipológica, tecnológica y estratigráficamente hablando. Las terrazas intermedias también han aportado evidencias arqueológicas que nos permiten rellenar los espacios cronológicos y culturales aun aceptando lo endeble que resulta hablar de diferencias entre las posibles subdivisiones internas de cada una de las culturas aquí representadas. Esta es una línea de investigación que deberá continuarse y que nosotros simplemente apuntamos. No se trata tanto de aplicar de manera rígida, el tradicional esquema de glaciarismo a la secuencia fluvial y de ello extraer conclusiones cronológicas o, lo que aun es más discutible, culturales; sino más bien, y ello debe ser entendido de una manera clara para evitar rendirse a críticas, a veces sin demasiado fundamento, intentar establecer un orden estratigráfico en el que se inserten los materiales líticos y cuyas diferencias puedan ser puestas en relación con los distintos niveles sedimentológicos. Esto se puede hacer y en las terrazas de la cuenca media del río Nalón existen datos para intentarlo. Nosotros simplemente lo planteamos a modo de línea de investigación.

En esta zona nuestros esfuerzos de trabajos de campo se han dirigido a dos lugares en concreto en los que, además, sus características los hacen diferentes e individualizan y señalan los dos tipos de yacimientos que hemos definido en esta área. Una terraza fluvial, en Paredes, relacionada con el río Nora dentro de la cuenca del Nalón, nos marca algunas de las características ya apuntadas y recalca lo asumido del establecimiento humano en las terrazas fluviales como zonas en las que las soluciones a los problemas más acuciantes encuentran más fácil y cómoda solución. Aquí no se puede hablar de un establecimiento permanente sino que, debido 
a lo escaso del material recuperado, entre el que los núcleos y las lascas son abundantes, nos inclinamos más por entenderlo como un lugar de parada corta en el que las labores de taller han estado presentes.

Otro sitio, el de Llagú, nos sitúa en un valle interior dentro de la misma cuenca general, relacionado con otro de los afluentes del Nalón, tal que es el río Gafu. Se trata de un interesante lugar de asentamiento en un valle formado a expensas de un elemental sistema cárstico y cuyo río, actualmente arroyo, desagua tras discurrir por el interior del mencionado sistema. El desagüe del pequeño valle se tapona de forma natural con materiales del mismo valle y la inundación que necesariamente sigue hace que se forme una pequeño lago o encharcamiento, al borde del cual se estableció un pequeño grupo humano. Allí seguramente se encontraría con abundante caza que acudiría a la mencionada zona lacustre y podría haber desarrollado sus sistemas de predación. Nuestra intención aquí, no obstante, tampoco es la de hablar de un cazadero pues, entre otras cosas, no se han recuperado restos faunísticos que lo demuestren y mientras tanto esto no suceda debe mantenerse una cierta cautela. Nosotros exponemos los datos arqueológicos dentro de un contexto medioambiental aportando una primera explicación y una posible interpretación.

Espacios abiertos en terrazas fluviales relacionadas con la costa o en desembocaduras de los ríos; en terrazas fluviales interiores o en valles pequeños interiores y resguardados en espacios muy cerrados, es donde hemos encontrado, hasta ahora, las evidencias arqueológicas y por ello definimos, a grandes rasgos, en estos sitios los tipos de yacimientos conocidos. Ir más allá en esta diferenciación de lugares seguramente es válido y los estudios pormenorizados y en detalle de las series líticas lo permitirán pero ello hoy, con lo parcial y todavía elemental de nuestras investigaciones, resulta prematuro.

\section{MATERIALES}

Ya hemos mencionado la carencia de materiales faunísticos que, unida a otras, no menos importantes insuficiencias, hace que sólo dispongamos del material lítico en nuestros yacimientos y sólo con él debamos intentar la reconstrucción de tan lejanas etapas prehistóricas. En Asturias únicamente se dispone de datos antropológicos, aun sin definir bien y sin situar taxonómicamente de una manera precisa, y con cronologías todavía muy ambiguas. Se trata de los restos antropológicos rescatados de la cueva del Sidrón cuyo descubrimiento y extracción ha estado rodeado de una fuerte polémica, totalmente absurda y estéril que se ha trasladado a las primeras clasificaciones y valoraciones científicas y que no ha ayudado, en absoluto, a situarlos bien en una escala antropológica. Se trata de una importantísima colección de más de 130 restos óseos entre los que destacan dos mandíbulas, varios dientes sueltos y otros importantes huesos como un húmero, un hioides, etc., que han permitido determinar, al menos, tres individuos distintos. Los estudios de estos restos (Rosas \& Aguirre e.p.; Cabo \& Egocheaga 1999; Rodríguez García \& Egocheaga 1999; Trabazo \& Egocheaga 1999) los sitúan entre los neandertales antiguos y se les asignan cronologías que, aunque se encuentran aun muy poco ajustadas, se sitúan cercanas a los 120.000. Estos restos estaban acompañados de escasos materiales líticos muy poco diagnósticos por lo que, en este caso, las apreciaciones tecnotipológicas no han de ser tenidas en cuenta más que de una manera general. No obstante, este descubrimiento nos permite acercarnos de una manera muy importante a las poblaciones del pleistoceno Medio y Superior antiguo en Asturias. Restringir estos datos antropológicos a los yacimientos en cueva y a una determinada etapa cultural más relacionada con el Musteriense y no verlos de una forma más general que afecte a esta época del Pleistoceno sería una imperdonable forma de analizar de manera miope el estudio de tan importantes restos. El hecho de que hayan aparecido en cueva y no al aire libre debe, sin duda, ser tenido en cuenta y como ya se ha dicho y en el encabezamiento de este artículo hemos transcrito una cita de Vallespí (1989) en este sentido, refiriéndose al paleolítico medio, las industrias de los yacimientos al aire libre y los yacimientos en cueva son diferentes. ¿Pero hemos de ver también poblaciones diferentes? Francamente creemos que no. Y mucho menos en 
etapas que clasificamos como achelenses. Pensamos que se trata simplemente de adaptaciones a diferentes medios y cuyos resultados tal como los vemos hoy, de una manera muy parcial, pueden inducirnos a error. Ni todo el paleolítico Antiguo del Cantábrico debe reducirse a la cultura musteriense, ni las poblaciones neandertales antiguas deben relacionarse sólo y únicamente con esta cultura.

Sinceramente pensamos que antes de las etapas musterienses, cada vez mejor definidas, hay una población muy extendida y muy importante en el Cantábrico que hemos llamado achelense y cuyas características en lo referente a su industria podemos sintetizarlas a grandes rasgos en lo siguiente: tecnológicamente son industrias realizadas con técnicas de percusión directa, sin preparación, salvo casos muy excepcionales y que deben ser estudiados con sumo cuidado, como son los referidos a la técnica levallois y ante los que mantenemos una más que lógica reserva, aunque como tales hemos clasificado diferentes piezas y núcleos. Los cantos rodados, marinos o fluviales, son los soportes más importantes y la tipología vendrá muy determinada por ellos, de manera que bifaces en canto o en grandes lascas extraídas de cantos marcan el mayor número porcentual. Esta técnica seguida de retalla y retoque hace que se logren piezas muy elaboradas en las que aspectos como la simetría y determinadas formas cobran gran importancia. La presencia de percutor blando, que ya hemos puesto en duda en otras ocasiones, no se nos antoja necesaria para la confección de estos acabados, aunque ello no invalida su aplicación. Simplemente es que no hemos encontrado ninguna prueba arqueológica que la evidencie. Los núcleos, numerosos en casi todas las series estudiadas, son principalmente globulosos, debido al soporte de los cantos a partir de los cuales se han realizado. También hay núcleos, aunque en menores proporciones, más elaborados como algunos de tortuga, levallois o musterienses. Para conseguir grandes lascas, la percusión lanzada cumple este objetivo cómodamente.

Los tipos representados en las series líticas son los cantos tallados con sus variantes unifaciales y bifaciales o los esferoides; los bifaces, en formas relacionadas con el soporte, que como hemos dicho es el canto rodado; los hendidores fabricados en lascas de tamaño grande y mediano, extraídas de los cantos, seguramente mediante la percusión lanzada; los picos triedros, muy relacionados en sus formas con los cantos rodados. Entre los materiales en lasca, se encuentran representados casi todos los tipos definidos tradicionalmente, aunque como es lógico, sus características se adaptan a la materia prima que siempre es la cuarcita, dándose una ausencia casi absoluta de materiales hechos en sílex. Raederas, en sus distintas variantes, con un cierto predominio de las simples convexas, lo que por otra parte es lógico en la simple fabricación de estos instrumentos. Muescas y denticulados en porcentajes importantes nos ponen en contacto con la más que probable fabricación de útiles en madera. En Cabo Busto, por ejemplo, hemos podido determinar el diámetro de los posibles astiles de madera gracias a la serie importante de muescas recuperada en las excavaciones de este yacimiento. Perforadores, raspadores y cuchillos de dorso forman otro grupo que, aunque en menores proporciones, se encuentra presente. Puntas, en sus diferentes variantes que responden a sus formas o a las técnicas empleadas para su fabricación como las puntas levallois, las puntas alargadas, las puntas musterienses, etc. no son grupos numerosos pero sí se encuentran representados. Un gran capítulo muy numeroso lo constituyen las lascas muy variadas y con características muy diferentes en cuanto a su elaboración, aunque el capítulo más importante en este apartado lo constituyen las lascas simples y las de decorticado primario sin preparación del talón, que responden a los simples levantamientos de la talla en los cantos.

Un particular problema que no, por haber sido muy a menudo señalado, deja de tener una crucial importancia, es la tiranía en formas y en técnicas del soporte para la fabricación de los artefactos que, ya lo hemos señalado, son los cantos. Entre otros aspectos, no menos importantes, se encuentra el problema de los retoques, y por añadidura de todos los instrumentos que se caracterizan por algún tipo de retoque. La lectura de éstos no solo no es fácil sino que, en no pocas ocasiones, se han interpretado como tales simples melladuras o desconchados de la propia cuarcita y en otras, llevados de un excesivo celo, no se han leído como retoques, precisamente por mantener estas dudas. Por ello, las líneas de separación entre, por ejemplo, lascas y raederas 
que viene marcada por la presencia o ausencia de retoques se nos antoja, muchas veces, como algo difícilmente salvable. No es nada fácil definir los retoques en la cuarcita, al contrario de lo que ocurre en el sílex.

Como se ve, se trata de series muy elementales, en cuanto a tecnología se refiere, en las que se encuentran representados los dos modos industriales más simples definidos por Carbonell (1987) y Carbonell et al. $(1983 ; 1984)$ adaptados a las características de la materia prima.

Hemos definido (Rodríguez Asensio 1999) las características de la cadena lítica en Asturias que, aunque no se puede entender como definitiva, sí puede acercarnos a la complejidad, no demasiado grande, de la fabricación de las industrias en estas épocas. Las hemos caracterizado dentro de una cierta Simplicidad, con una Alta uniformidad y Escasa especialización técnica. Todo ello nos acerca a la Inmediatez como aspecto más importante en la captación de los recursos, en la elaboración de los mismos y en la utilización de los artefactos como resultado final del proceso técnico. Es decir, la materia prima se obtiene en forma de cantos en el mismo sitio o en sus inmediaciones, por lo que buscar otros sitios de potencial cantera no tiene sentido; después, en el mismo sitio se extraen las grandes lascas que serán trasladadas con los cantos al lugar del asentamiento, en caso de ser necesario, y allí se confeccionan los útiles en piedra que sirven para fabricar otros artefactos en otras materias como es la madera. Sólo serán estos últimos los únicos que se transporten. Los materiales líticos quedan en el lugar tras haberse usado. Este elemental proceso es el que se repite constantemente en el deambular por los territorios o zonas que hemos descrito y es la causa de que se encuentren concentraciones de materiales con tipología y tecnología muy similar.

\section{SECUENCIA CULTURAL Y CRONOLOGÍA}

Proponemos, a continuación, una ordenación cronológica y cultural que se encuentra basada en los yacimientos estudiados, en superficie y en cueva, desde el poblamiento más antiguo fehacientemente constatado en Asturias hasta la llegada del homo sapiens y las nuevas culturas del paleolítico Superior.

Etapa 1. Poblamiento humano antiguo, en el pleistoceno Medio, atestiguado en el yacimiento de Cabo Busto, en el nivel $\mathrm{V}$, con industrias en cantos tallados y que hemos situado de manera provisional entre los 500.000 y los 300.000 años. Se han recuperado evidencias arqueológicas en otros sitios de Asturias que, aunque no han sido objeto de excavaciones ni de estudios pormenorizados, sí se pueden relacionar entre sí. Se trata de las terrazas más altas del Nalón. En una zona del interior de la terraza fluvial de $90 \mathrm{~m}$ se han recuperado restos industriales líticos que presentan tipologías muy arcaicas, aunque, de momento, sea necesario mantener las lógicas reservas hasta tanto no se realicen los correspondientes estudios detallados en materia arqueológica. Geológicamente se puede establecer una relación entre este nivel de aterrazamientos del Nalón y el nivel V de Cabo Busto lo que vendría, además, apoyado por las evidencias arqueológicas que estamos indicando. Esta etapa de primer poblamiento la hemos situado, dentro de nuestro contexto, en el estadio isotópico13, basándonos en los datos geológicos de estudio de la Rasa litoral cantábrica. Son escasos aun los datos de que se dispone para la definición más concreta de este momento, pero ellos nos permiten enunciarlo y situarlo dentro de un margen todavía grande. En el resto del norte peninsular no se conocen, de momento, industrias con estas características, ni tipológicas ni cronológicas. Solamente se han apuntado evidencias antiguas, más o menos relacionadas con las cronologías aquí propuestas, en Galicia, donde los recientes trabajos de prospección en las terrazas fluviales del Miño permiten trasladar hacia esas fechas algunos de los materiales líticos recuperados (Cano 1997; 1999), lo que, por otra parte, nos fortalece en nuestras antiguas apreciaciones (Rodríguez Asensio 1983) de que la cornisa cantábrica fue poblada, al menos inicialmente, desde el Occidente. Se trataría de una población poco extendida que quizás no haya cuajado y tras la cual se produciría un vacío poblacional en la Cornisa cantábrica. 
Etapa 2. Momento achelense que hemos situado cronológicamente en el último interglaciar Riss-Würm y que, seguramente, continuaría en los primeros momentos de la glaciación würmiense. El punto de referencia que nos sirve para situar sedimentológicamente este momento en Asturias lo encontramos en Bañugues, donde Hoyos (ver Jordá 1977) determinó un paleosuelo del Würm I que se encuentra por encima de los restos arqueológicos asignables al Achelense. Este momento está muy extendido no solo en Asturias sino en el resto de la cornisa cantábrica y nos indica que el clima interglacial, de una cierta bonanza, permitiría el establecimiento exterior y aún no se habría producido la entrada en las cuevas. Lo situamos en el estadio isotópico 5, en general, con cronologías entre el 127.000 y 72.000 sin que por el momento podamos concretarlo más en los diferentes yacimientos. Las industrias de este momento, tal como hemos indicado, se basan en artefactos a partir de cantos rodados y una tipología no muy variada pero con suficientes tipos para hablar de una cierta diferenciación instrumental. No ha de extrañarnos esta aparente monotonía en las industrias durante un lapso de tiempo grande y por ello no debemos caer en tentaciones de intentar subdivisiones internas basadas en rígidos planteamientos tipológicos. Si es aceptado "el millón de años del aburrimiento" para Europa, no ha de extrañarnos que durante el período anterior al Würm las industrias sean muy similares y monótonas. Las posibles subdivisiones internas de esta etapa nunca vendrán de las industrias, sino de los estudios paralelos como la sedimentología, fauna (macro y micro, en caso de haberla), polen (en caso de haberlo) etc. Hoy por hoy no se ha recuperado nada en ese sentido. En esta misma época, en determinadas ocasiones, y quizás para usos muy concretos y específicos, se ocupan algunas cuevas, como es el caso de la cueva de El Sidrón en la que no se ha encontrado yacimiento pero sí restos humanos. Quizás ello se deba a una cierta especialización relacionada con alguna actividad concreta, como por ejemplo, "enterramientos" u otro tipo de práctica especializada, y no se trate de asentamiento humano, sensu stricto, que se encontraría en el exterior. Esta cultura achelense, que hemos situado en sus momentos finales dentro del paradigma clásico, se relacionaría desde el punto de vista antropológico con formas anteneandertales o neandertales antiguos, que de esta manera han sido clasificados estos restos óseos de El Sidrón.

Etapa 3. Musteriense que situamos cronológicamente desde los primeros momentos de la glaciación würmiense hasta el segundo estadio de la misma, que numéricamente se correspondería desde un 72.000 hasta un 40.000, entendiendo estas fechas de una manera global. En este momento, podemos separar dos tipos de musterienses que, más que facies en el esquema de Bordes, se relacionan con el medio en el que se desarrollan, es decir, un Musteriense de tradición achelense que hunde sus raíces en el Achelense anterior y que, sin solución de continuidad, se desarrolla en todo el territorio, al aire libre, con industrias muy relacionadas con las fases anteriores con las que debe ser unido indiscutiblemente. Ejemplo de este tipo lo encontramos en el sitio de Sardín (Rodríguez Asensio 1983). Este Musteriense, a medida que el clima de los primeros momentos glaciales se enfría, va entrando en las cuevas y desarrolla un Musteriense en cueva que, aunque se denomine Musteriense de tradición achelense, se diferencia algo del anterior, precisamente por que su medio, como hemos dicho, varía del exterior a las cuevas. De este último, los ejemplos del abrigo de La Viña (Fortea1998) y de la cueva de Llonín (Fortea et al. 1998) nos parecen representativos. No hemos de ver una excesiva rigidez en este esquema y al decir que el Musteriense de tradición achelense en cueva se relaciona con el Musteriense de tradición achelense al aire libre hemos de ampliar la zona de relación y no restringirla, por lo que la idea expuesta se refiere más al norte cantábrico que a una zona determinada.

El final de este proceso, todavía difícil de matizar cronológicamente, se situaría en los comienzos del paleolítico Superior, representados quizás por el Chatelperroniense hace 38.000. Hasta esos momentos se puede seguir, por tanto, una cierta continuidad, al menos en el norte peninsular. 


\section{BIBLIOGRAFÍA}

ALTUNA, J. (1992): "El medio ambiente durante el Pleistoceno Superior en la región Cantábrica con referencia especial a sus faunas de mamíferos", Munibe 43: 13-29. San Sebastián.

BALDEÓN, A. (1987): El Paleolítico Medio en el País Vasco. Tesis Doctoral. Universidad de Deusto. Bilbao BALDEÓN, A. (1990): "El Paleolítico inferior y medio en el País Vasco. Una aproximación en 1990", Munibe 42: 11-22. San Sebastián.

BALDEÓN, A. (1993): "El yacimiento de Lezetxiki (Guipúzcoa, País Vasco). Los niveles musterienses", Munibe 45: 3-97. San Sebastián.

BALDEÓN, A. (1999): "El abrigo de Axlor (Bizkaia, País Vasco). Las industrias líticas de sus niveles Musterienses", Munibe 51: 9-121. San Sebastián.

BARRERA LOGARES, J. M. (1998): Estudios sobre el Paleolítico antiguo en Asturias. Historiografía del Paleolítico antiguo asturiano. Trabajo de Tercer Ciclo. Depto. de Historia. Universidad de Oviedo.

BORDES, F. (1950): "L'évolution buisonnante des industries en Europe occidentale. Considerations theoriques sur le Paléolithique ancien et moyen", L'Anthropologie 54: 393-420. Paris.

_ (1950): "Essai de classification des industries Mousteriennes", Bulletin de la Société Préhistorique Française 50: 457-466. Paris.

- (1961): "Mousterian cultures in France", Science 134: 803-810.

BORDES, F. \& BOURGON, M. (1951): “Le complexe Moustérien: Moustérien, Levalloisen, et Tayacien”, L'Anthropologie 55: 1-23. Paris.

CABO, L. \& EGOCHEAGA, J.E. (1999): "Breve nota sobre el Húmero 1 de la cueva de El Sidrón (Cadanes, Piloña, Asturias)", XI Congreso de la Sociedad Española de Antropología Biológica. Santiago de Compostela.

CABRÉ, J. (1915): El Arte rupestre en España. C.I.P.P. Mém. № 1. Madrid.

CABRERA, V. (1983): "Notas sobre el Musteriense cantábrico: el Vasconiense" Homenaje al Prof. Dr Martín Almagro Basch, 1: 131-134. Ministerio de Cultura. Madrid.

- (1984): El yacimiento de la cueva del Castillo (Puente Viesgo, Santander). Bibliotheca Praehistórica Hispánica. XXII. Madrid.

CANO PAN, J. A.; AGUIRRE ENRÍQUEZ, E.; GILES PACHECO, F.; GRACIA PRIETO, J.; SANTIAGO PÉREZ, A.; MATA ALMONTE, E.; GUTIÉRREZ LÓPEZ, J.M.; DÍAZ DEL OLMO, F.; BAENA ESCUDERO, R. \& BORJA, F. (1997): "Evolución del Pleistoceno en la cuenca baja del Miño, sector La Guardia-Tuy. Secuencia de los primeros poblamientos humanos y registro arqueológico", Actas Cuaternario Ibérico: 201-212. Huelva.

CANO PAN, J. A.; AGUIRREENRÍQUEZ, E.; GILES PACHECO, F.; GRACIA PRIETO, J.; SANTIAGO PÉREZ, A.; MATA ALMONTE, E.; GUTIÉRREZ LÓPEZ, J.M.; AGUILERA RODRÍGUEZ, L. \& PRIETO REINA, O. (1999): "Secuencia cronoestratigráfica y poblamiento paleolítico en la cuenca media-baja del río Miño. Sector Tuy (Pontevedra)-Cortegada (Orense)", Avances en el Estudio del Cuaternario Español. X Reunión Nacional de Cuaternario: 231-240. Girona.

CANOPAN, J. A.; GILES PACHECO, F.; AGUIRREENRÍQUEZ, E.; SANTIAGO PÉREZ, A.; GRACIA PRIETO, F. J.; MATA ALMONTE, E.; GUTIÉRREZ LÓPEZ, J.M. \& PRIETO REINA, O. (1999): "Technocomplexes of lithic industries of the Middle palaeolhic in the northwest of the iberian peninsula", Gibraltar and the Neanderthals 1848-1998. Oxford Books.

CARBONELL, E. (1987): "Human development in the framework of the Lithic Operative Chains", Sistemes d'analisis en Prehistoria: 68-82. Girona-Bordeaux-Poitiers. C.R.P.E.S.

CARBONELL, E.; GUIBAULT, E. \& MORA, R. (1983): "Utilización de la lógica analítica para el estudio de los tecnocomplejos de cantos tallados", Cahier Noir 1: 1-64. Vitoria. 
JOSÉ ADOLFO RODRÍGUEZ ASENSIO

CARBONELL, E.; GUIBAULT, E. \& MORA, R. (1984): “Amplification du système analytique avec la classification des tecno-complexes à galets taillés", Bulletin de la Societé Préhistorique Français 81: 203-206.

FORTEA, J. (1998): “Abrigo de La Viña. Informe y primera valoración de las campañas de 1995 a 1998”, Excavaciones Arqueológicas en Asturias, 1995-98: 32-41. Servicio de Publicaciones del Principado de Asturias. Oviedo.

FORTEA PÉREZ, J.; RASILLA VIVES, M. de la \& RODRÍGUEZ OTERO, V. (1998): "La cueva de Llonín (Llonín, Peñamellera Alta). Campañas de 1995 a 1998”, Excavaciones Arqueológicas en Asturias, 1995-98: 59-68. Servicio de Publicaciones del Principado de Asturias. Oviedo.

FREEMAN, L. (1969-70): “El Musteriense cantábrico. Nuevas perspectivas”, Ampurias 31-32: 55-69. Barcelona.

_ (1977): "Contribución al estudio de los niveles paleolíticos de la cueva del Conde", Boletín del Instituto de Estudios Asturianos 90-91: 447-489. Oviedo.

- (1980): "Mousterian occupations at the cueva del Pendo". Ed. J. González Echegaray: El Yacimiento de la cueva del Pendo. Bibliotheca Paehistorica Hispana XVII: 29-71. Madrid

GAMBLE, C. S. (1990): El poblamiento paleolítico de Europa. Ed. Crítica. Barcelona. Trad. Castellana.

GONZÁLEZ ECHEGARAY, J. \& FREEMAN, L. (1971): Cueva Morín. Publicaciones del Patronato de las Cuevas Prehistóricas de la Provincia de Santander. Mém. VI. Santander.

- (1973): Cueva Morín. Publicaciones del Patronato de las Cuevas Prehistóricas de la Provincia de Santander. Mém. X. Santander.

GONZÁLEZFERNÁNDEZ, J.M.(1968): "El Paleolítico inferior y medio en Asturias. Nuevos hallazgos", Archivum XVIII: 1-36. Oviedo.

HERNÁNDEZPACHECO, F.; LLOPIS, N.; JORDÁ CERDÁ, F. \& MARTÍNEZ, J.A. (1957): Livret-guide de l'excursion $n^{\circ}$ 2. Le Quaternaire de la Region Cantabrique. $\mathrm{V}^{\circ}$ Congres International INQUA. Diputación provincial. Oviedo.

HOYOS, M. (1981): "Estudio Geológico de la Cueva de las Caldas" en CORCHÓN, S.: Cueva de Las Caldas (San Juan de Priorio. Oviedo). Excavaciones Arqueológicas en España 1981: 14. Madrid.

JORDÁ CERDÁ, F. (1955): "Notas sobre el Musteriense en Asturias", Boletín del Instituto de Estudios Asturianos XXV: 1-24. Oviedo.

JORDÁ CERDÁ, F. (1977): La Prehistoria. Historia de Asturias I. Ayalga Ed. Oviedo.

MÁRQUEZ URÍA, M. C. (1977): "Las excavaciones del conde de la Vega del Sella en la cueva del Conde (Tuñón. Asturias)", Boletín del Instituto de Estudios Asturianos 90-91: 431-446. Oviedo.

MITHEN, S. (1998): Arqueología de la mente. Orígenes del arte, de la religión y de la ciencia. Drakontos. Crítica (Grijalbo Mondadori, S.A.) Barcelona.

MONTES BARQUÍN, M. (1993): Los Complejos industriales del paleolítico inferior en el centro de la región cantábrica. Trabajo de Inv. tercer Ciclo. Universidad de Cantabria. (ejemplar mecanografiado).

MONTES BARQUÍN, M. (1993): "Los yacimientos costeros del Paleolítico inferior en el centro de la Región Cantábrica”, Nivel Cero 4: 6-27. Ed. Attica. Santander.

MONTES BARQUÍN, M. (1998): Los Complejos industriales del Paleolítico inferior en la Región Cantábrica. Tesis Doctoral. Universidad de Cantabria. Santander, 1998. (ejemplar mecanografiado).

OBERMAIER, H. (1916): El Hombre Fósil. C.I.P.P. Mém. No 9. Madrid.

RODRÍGUEZ ASENSIO, J. A. (1983): La presencia humana más antigua en Asturias. Estudios de Arqueología Asturiana $\mathrm{n}^{\circ} 2$. Oviedo.

(1995): "Excavaciones Arqueológicas en Cabo Busto (Valdés). Un asentamiento achelense", Excavaciones Arqueológicas en Asturias. 1990-94: 7-18. Servicio de Publicaciones del Principado de Asturias. Oviedo. 
(1996): "Estratigrafía del yacimiento de Busto (Valdés). Una secuencia del Pleistoceno medio en Asturias", Bol. R.I.D.E.A. 148: 367-383. Oviedo.

(1997): "Yacimiento de Louselas (Ribadeo. Lugo). Un Conjunto lítico del paleolítico antiguo", Fervedes 4. Villalba. Lugo.

(1998): "El yacimiento de Cabo Busto (Valdés. Asturias). Una secuencia del Pleistoceno medio en el norte peninsular", Spal 5: 19-43. Sevilla.

(1998): "Excavaciones en el yacimiento de Cabo Busto(Valdés). Memoria de 1995 a 1998", Excavaciones Arqueológicas en Asturias 1995-98: 13-24. Servicio de Publicaciones del Principado de Asturias. Oviedo

_ (1999): "Le gisement paléolithique ancien de Cabo Busto (Asturies. Nord de la Péninsule Ibérique)", L'Anthropologie, tome 103, 3: 327-341. Paris.

(2001): El yacimiento de Cabo Busto. Los orígenes prehistóricos de Asturias. GEA/2000. Gijón/Luarca.

RODRÍGUEZ ASENSIO, J.A. y NOVALFONSECA, M.A. (1998): Gijón antes de Gijón. Breve aproximación a los primeros predadores en la Prehistoria asturiana. Gran Enciclopedia Asturiana. GEA/2000. Gijón.

RODRÍGUEZ ASENSIO, J.A.; NOVAL FONSECA, M.A. \& BARRERA LOGARES, J.(1999): "Estratigrafía del Pleistoceno medio-superior en la Rasa Litoral Cantábrica (Asturias)", Avances en el estudio del Cuaternario español : 253-258. L. Pallí Buxó y C. Roqué Pau (editores). Girona.

RODRÍGUEZ GARCÍA, L. \& EGOCHEAGA RODRÍGUEZ, J.E. (1999): "Dientes aislados del 'Hombre del Sidrón' (Cadanes. Piloña. Asturias)”, XI Congreso de la Sociedad Española de Antropología Biológica. Santiago de Compostela.

ROSAS, A. \& AGUIRRE, E. (e.p.): "Restos humanos Neandertales de la Cueva de El Sidrón (Piloña. Asturias). Nota preliminar".

TRABAZO, R. \& EGOCHEAGA, J.E. (1999): "Resultados preliminares del análisis tafonómico de los restos de El Sidrón: I-Autotopismo de los fósiles e identificación del yacimiento", XI Congreso de la Sociedad Española de Antropología Biológica. Santiago de Compostela.

VALLESPÍ PÉREZ, E. (1989): "Paleolítico medio indeterminado, de aspecto postachelense, en ámbitos fluviales del sur y centro de la península Ibérica", Veleia 6: 7-20. Vitoria. 

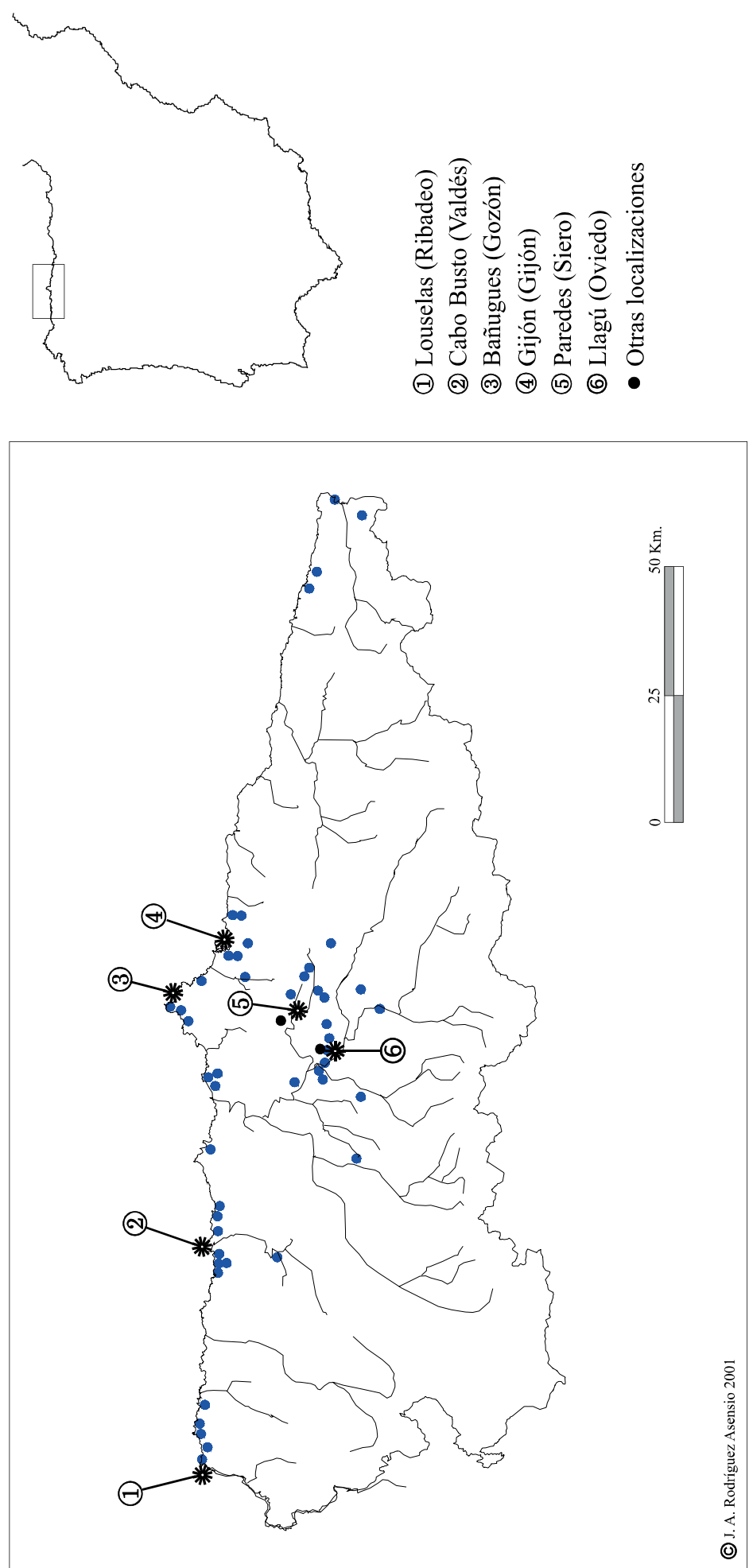

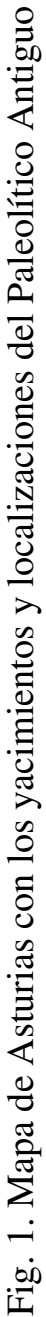




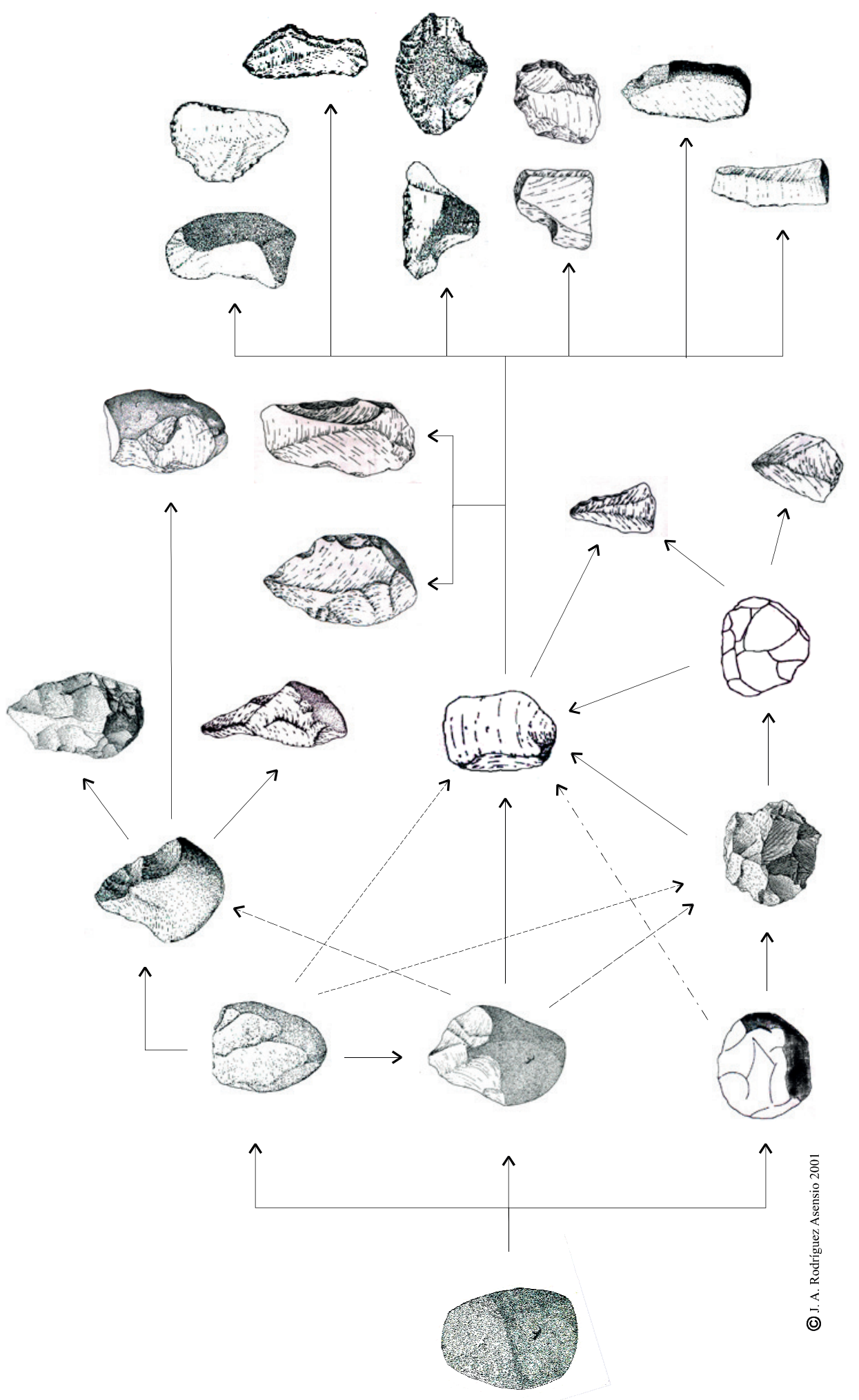

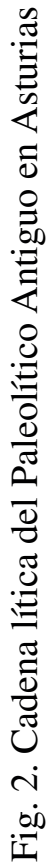

ISSN: 1133-4525 ISSN-e: 2255-3924

SPAL 9 (2000)

http://dx.doi.org/10.12795/spal.2000.i9.05 